AN MED INTERNA (Madrid) Vol. 17, N. $^{\circ} 12$, pp. 657-659, 2000

\title{
Absceso hepático piogénico como complicación de la enfermedad de Crohn
}

\author{
E. MARTÍN-PÉREZ, A. GALVÁN, E. LARRAÑAGA, J.M. FIGUEROA, \\ P.A. SERRANO
}

Servicio de Cirugía General y Aparato Digestivo. Hospital Universitario de la Princesa. Madrid

\begin{abstract}
RESUMEN
El absceso hepático piogénico es una complicación infrecuente de la enfermedad de Crohn que presenta una alta mortalidad si el diagnóstico y tratamiento no se realizan de forma temprana. Los abscesos abdominales, fístulas o tratamiento con esteroides son factores predisponentes en la patogenia de esta entidad. Presentamos el caso de un paciente con enfermedad de Crohn y abscesos hepáticos múltiples en el lóbulo hepático derecho sin factores predisponentes claros. El diagnóstico de absceso hepático fue establecido por TAC y el paciente fue tratado con drenaje percutáneo. Es importante considerar esta rara complicación debido a que el diagnóstico es difícil de hacer y se requiere un alto grado de sospecha. Una vez sospechado, hay que realizar un estudio exhaustivo e instituir el tratamiento adecuado. La mayoría de los pacientes con absceso hepático pueden ser manejados con éxito por drenaje percutáneo combinado con tratamiento antibiótico si el diagnóstico se ha realizado antes de que se haya producido necrosis extensa.
\end{abstract}

PALABRAS CLAVE: Absceso hepático. Enfermedad de Crohn. Drenaje percutáneo.

\author{
PYOGENIC LIVER ABSCESS AS A COMPLICATION OF CROHN'S \\ DISEASE
}

Martin-Perez E, Galvan A, Larrañaga E, Figueroa J.M, Serrano P.A. Absceso hepático piogénico como complicación de la enfermedad de Crohn. An Med Interna (Madrid) 2000; 17: 657-659.

\section{INTRODUCCION}

El absceso hepático es una complicación infrecuente de la enfermedad de Crohn que puede estar asociado con una alta mortalidad (1,2). Las complicaciones secundarias a la enfermedad de Crohn tales como la perforación, absceso abdominal o fístula se consideran como factores que intervienen en la patogénesis de esta entidad (2), pero debido a que los síntomas que presenta el absceso hepático como la fiebre, dolor abdominal y anorexia ocurren frecuentemente en pacientes con enfermedad de Crohn activa, el diagnóstico suele retratarse y se requiere un alto grado de sospecha con el fin de instituir un tratamiento temprano. Presentamos el caso de un paciente con enfermedad de Crohn complicada con absceso hepático sin clara patología predisponente discutiendo los posibles mecanismos etiopatogénicos, los problemas diagnósticos y las opciones terapéuticas.

\section{CASO APORTADO}

Varón de 38 años, con antecedentes de enfermedad de Crohn de 3 años de evolución e ingresado en dos ocasiones por episodios de obstrucción intestinal que fueron tratados médicamente sin necesidad de cirugía. Desde su última admisión, 6 meses antes, el paciente había permanecido asintomático y dos semanas antes del ingreso, el paciente consultó a su médico de cabecera por fiebre y diarrea y se pensó que padecía de una exacerbación de la enfermedad de Crohn recibiendo tratamiento con corticoides sin mejora objetivable. Ante la persistencia de la fiebre, acude a urgencias con escalofríos, vómitos, anorexia y dolor en hipocondrio derecho.

A la exploración, el paciente estaba febril $\left(39^{\circ} \mathrm{C}\right)$ con mal estado general, y abdomen distendido y doloroso en hipocondrio derecho pero sin hepatomegalia. La exploración cardiopulmonar era normal. En el hemograma se observó leucocitosis de $26.500 / \mathrm{mm}^{3}$ con desviación a la izquierda, hemoglobina de 10,6 g/l, hematocrito 36,3\%, plaquetas 490.000 y velocidad de sedimentación de $50 \mathrm{~mm} / \mathrm{h}$. La

Trabajo aceptado: 22 de Abril de 1999 
bioquímica sérica demostró niveles normales de transaminasas y fosfatasa alcalina, creatinina y urea. La RX de tórax era normal. La TAC abdominal puso de manifiesto la existencia de múltiples abscesos en el lóbulo hepático derecho (Fig. 1). No se identificaron otros abscesos abdominales ni alteraciones de la vesícula biliar, vía biliar ni páncreas. Se inició tratamiento intravenoso empírico con Gentamicina $80 \mathrm{mg}$ cada 8 horas y Clindamicina $600 \mathrm{mg}$ cada 8 horas. Antes del tratamiento definitivo del absceso se realizó un estudio detallado para identificar la causa del absceso hepático. En la colonoscopia, no se observaron alteraciones y la evaluación radiológica del intestino delgado reveló varias estenosis a nivel de yeyuno e íleon pero sin evidencia de fístulas u obstrucción intestinal.

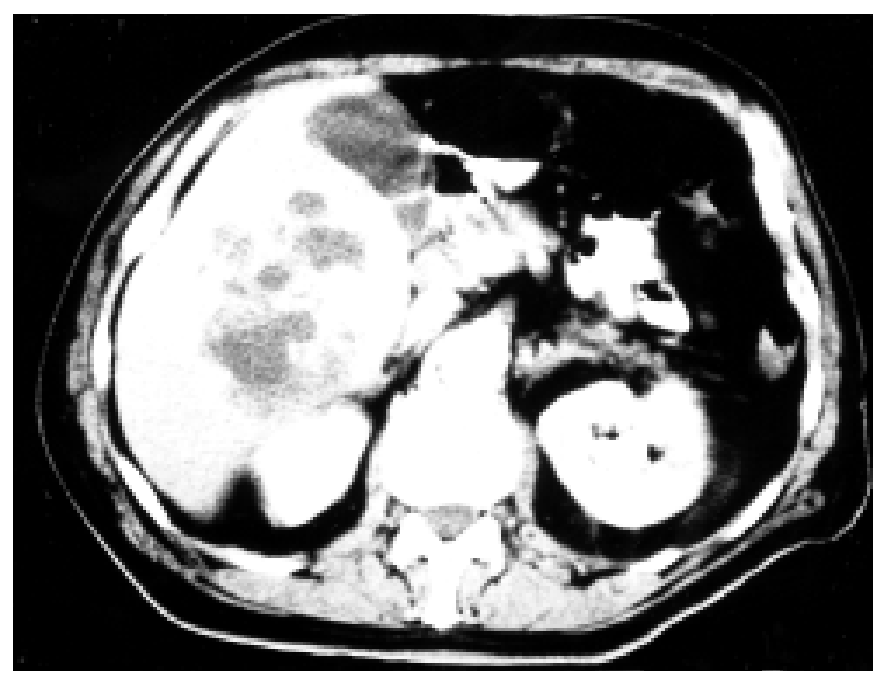

Fig. 1. TAC abdominal que muestra abscesos múltiples en el lóbulo hepático derecho.

El absceso hepático fue drenado bajo control ecográfico, tomándose muestras del contenido del absceso para cultivo donde creció Streptococcus milleri. Los hemocultivos fueron estériles. La antibioterapia intravenosa se continuó durante 6 semanas. El drenaje se mantuvo durante 21 días y se retiró cuando el drenaje fue mínimo. $\mathrm{Su}$ recuperación fue satisfactoria, y fue dado de alta una vez finalizado el tratamiento antibiótico. Una TAC abdominal realizada 4 meses después mostró colapso de las cavidades de los abscesos.

\section{DISCUSION}

El absceso hepático es una complicación rara de la enfermedad de Crohn que constituye alrededor del $8 \%$ de todos los abscesos hepáticos piogénicos (2) y se han publicado alrededor de 40 casos en la literatura, la mayoría como casos individuales (1-10). Uno de los datos que diferencian el absceso hepático en los pacientes con enfermedad de Crohn es la menor edad de los pacientes comparado con la población general, la prevalencia en varones, la presencia de abscesos múltiples y la existencia de una infección intraabdominal como perforación, absceso o fístula (1-4).

Los síntomas más frecuentes en pacientes con absceso hepático son fiebre, dolor abdominal y anorexia pero en pacientes con enfermedad de Crohn, toda esta sintomatología es lo habitual debido a la enfermedad, haciendo el diagnóstico difícil $(2,5,6)$. El hallazgo de leucocitosis como manifestación de una infección bacteriana sistémica, tampoco es útil debido a que estos pacientes presentan leucocitosis sobre la base de su enfermedad o de su tratamiento con corticoides. Por ello, en pacientes con enfermedad de Crohn, el diagnóstico de absceso hepático requiere un alto grado de sospecha porque la pobreza de signos y la naturaleza inespecífica de los síntomas hace fácil la confusión con una exacerbación de la enfermedad y el paciente puede ser tratado con dosis altas de esteroides o incluso con tratamiento quirúrgico actuando a nivel del segmento intestinal enfermo. En nuestro paciente, se consideró inicialmente que la enfermedad podía deberse a una exacerbación de la enfermedad de Crohn por lo que fue tratado con corticoides sin objetivar mejoría de su cuadro. Por ello, se ha sugerido que la fiebre, escalofríos, leucocitosis y una elevación de los niveles de fosfatasa alcalina alertarían al clínico hacia la posibilidad de esta complicación $(2,4)$.

Como método diagnóstico de imagen, la ecografía es el test más útil para la valoración inicial ante la sospecha de absceso hepático con una alta sensibilidad ( 85 a 95\%) y más seguro que la TAC en valorar la vía biliar y también permite el drenaje diagnóstico o terapéutico en el momento de realizarlo. La TAC es la técnica de imagen más sensible (95 a $100 \%$ ) que también permite la intervención diagnóstica o terapéutica. Con esta prueba se ha mejorado el diagnóstico y reducido el retraso diagnóstico (11-14).

En la población general, la enfermedad de la vía biliar es la causa más frecuente de absceso hepático $(4,14,15)$. Otras causas incluyen apendicitis, diverticulitis, sepsis generalizada, traumatismo, carcinoma de colon, quimioterapia y causas criptogénicas. En pacientes con enfermedad de Crohn, esta complicación parece estar relacionada con diversos factores como son las alteraciones inmunológicas implicadas en la enfermedad o el tratamiento con esteroides, la malnutrición, cirugía abdominal en los meses o años que preceden el desarrollo del absceso, los abscesos intraabdominales relacionados con el intestino o la presencia de fístulas entéricas o perforación del intestino, absceso perirrectal y lesiones menores de la piel que pueden ocasionar absceso hepático estafilocócico $(1,2,5,7)$. También se ha demostrado que el tratamiento con metronidazol puede predisponer a la formación de abscesos al alterar la flora intestinal (8). Nuestro paciente recibió tratamiento con corticoides durante varios días antes del diagnóstico de absceso hepático pero es probable que el absceso estuviera ya presente en este paciente cuando se inició tratamiento con esteroides. No se pudo identificar cirugía abdominal previa, trayecto fistuloso de intestino enfermo u otro origen de infección, contigua o distante que explicase el origen del absceso. La invasión directa de la vena porta por organismos que migran a través del intestino enfermo (pieloflebitis) parecería ser la ruta de infección en algunos casos. En esta condición, las venas mesentéricas en el lugar del proceso inflamatorio se trombosan y la infección se extiende en el sistema porta embolizando al hígado. El émbolo séptico bloquea las pequeñas venas y da origen a migración de leucocitos polimorfonucleares, linfocitos y macrófagos a la región y a una intensa reacción inflamatoria (1). Es más frecuente la localización del absceso en el lóbulo hepático derecho por un mayor flujo portal de la vena mesentérica al lóbulo derecho y a su mayor volumen $(1,14)$.

La microbiología en nuestro paciente es la típica de los abscesos hepáticos piogénicos ya que Streptococcus milleri aparece al menos en la mitad de todos los abscesos hepáticos 
piogénicos $(2,8,14,16)$. Moore-Gillon et al (16) estudiaron 16 abscesos hepáticos piogénicos consecutivos y aislaron $\mathrm{S}$. Milleri en 13 siendo el único organismo en 10 pacientes.

El drenaje del absceso junto con la administración de antibióticos sistémicos constituye la base del tratamiento de los abscesos hepáticos piogénicos. Aunque se ha evaluado la antibioterapia intravenosa como el tratamiento primario de los abscesos hepáticos (17), diversos autores han demostrado claramente que aquellos abscesos hepáticos piogénicos no sometidos a alguna forma de drenaje conllevan una mortalidad del $100 \%$ debido a que es difícil lograr los niveles bactericidas de antibióticos dentro del absceso. Por tanto, la administración de antibióticos es claramente un adyuvante del drenaje definitivo del absceso (18). En el pasado, el tratamiento del absceso hepático piogénico era la cirugía; sin embargo, en la actualidad el drenaje percutáneo mediante ecografía o TAC combinado con antibióticos, ha llegado a ser el tratamiento de elección en la mayoría de los centros $(1,7,9,14,18)$, con una tasa de éxito del $75 \%$ al $83 \%(5,9,11,12,18)$, aunque algunos autores todavía prefieren el drenaje quirúrgico (13).

Como ya se ha dicho, en pacientes con enfermedad de Crohn, son característicos los abscesos hepáticos múltiples que presentan problemas de manejo tanto por cirugía, drenaje percutáneo o ambos $(1,4)$. Koneru et al $(15)$ han sugerido que el drenaje quirúrgico es preferido en pacientes con abscesos hepáticos múltiples grandes debido a que la tasa de fallo y la estancia hospitalaria son menores que cuando se realiza drenaje percutáneo. Pero otros han demostrado que muchos abscesos que parecen ser múltiples o multiloculados en la TAC tienen libre comunicación entre las cavidades (18) y todas ellas pueden ser drenadas con un único catéter e incluso existe la posibilidad de colocar más de un catéter de forma percutánea para evacuar las cavidades no drenadas y de realizar drenajes percutáneos repetidos que están asociados con poco aumento de mortalidad (14). Es necesario por lo menos de 4 a 8 semanas de tratamiento antibiótico en los abscesos hepáticos únicos, y períodos de tratamiento mayores se han propuesto en pacientes con abscesos hepáticos múltiples.

El drenaje quirúrgico abierto todavía está indicado cuando el drenaje percutáneo no es posible técnicamente debido a la localización de los abscesos, si existe otra enfermedad intraabdominal que precise cirugía y después de fallo del drenaje percutáneo (18). La elección del tratamiento está determinada por la extensión de las lesiones intrahepáticas y las circunstancias clínicas bajo las cuales es diagnosticado. Algunos han sugerido que el drenaje percutáneo podría ser un tratamiento inadecuado debido a que la enfermedad existente en el intestino podría requerir resección (10). Nuestro paciente fue manejado satisfactoriamente con drenaje percutáneo sin resección intestinal. Otros artículos también aseveran la seguridad y eficacia de este manejo $(5,9)$ y ya que el $70-90 \%$ de los pacientes con enfermedad de Crohn serán sometidos a cirugía a lo largo de su vida, se debería evitar cualquier cirugía innecesaria.

En conclusión, la enfermedad de Crohn debería incluirse en el diagnóstico diferencial de las enfermedades que originan abscesos hepáticos, especialmente en gente joven. El diagnóstico temprano de esta complicación es difícil de realizar y se requiere un alto grado de sospecha. La mayoría de los abscesos hepáticos pueden ser manejados satisfactoriamente mediante drenaje percutáneo combinado con tratamiento antibiótico.

\section{Bibliografía}

1. Mir-Madjlessi S, McHenry M, Farmer R: Liver abscess in Crohn's disease. Gastroenterology 1986; 91: 987-993.

2. Vakil N, Hayne G, Sharma A, Hardy DJ, Slutsky A: Liver abscess in Crohn's disease. Am J Gastroenterol 1994; 89: 1090-1095.

3. Christophi C, Hughes ER: Hepatobiliary disorders in inflammatory bowel disease. Surg Gynecol Obstet 1985; 160: 187-193.

4. Greenstein AJ, Lowenthal BA, Hammer GS, Schaffner F, Aufses AH JR: Continuing changing patterns of disease in pyogenic liver abscess. A study of 38 cases. Am J Gastroenterol 1984; 78: 217-226.

5. Casola G, van Sonnenberg E, Neff CC, Saba R, Withers C, Emarine CW: Abscesses in Crohn's disease: Percutaneous drainage. Radiology 1987; 163: 19-22

6. Cohen J, Marim M, Rossi RL, Schoetz D: Liver abscess. The need for complete gastrointestinal evaluation. Arch Surg 1989;124:561-564.

7. Watts HD: Multiple hepatic abscesses complicating regional enteritis: The importance of prior surgery or corticosteroid therapy. Dig Dis Sci 1978; 23: 41-47.

8. Hatoff DE: Perineal Crohn's disease complicated by pyogenic liver abscess during metronidazole therapy. Gastroenterology 1983; 85: 194-195.

9. Darnell A, Brullet E, Campo R, Donoso Ll: Liver abscesses as initial presentation of Crohn's disease. Am J Gastroenterol 1995; 90: 1363-1364.

10. Crass J: Liver abscess as a complication of regional enteritis: Interventional considerations. Am J Gastroenterol 1983; 78: 747-749.

11. Kandel S, Marcon N: Pyogenic liver abscess: New concepts of an old disease. Am J Gastroenterol 1984; 79: 65-71.

12. Rustgi A, Ritcher J: Pyogenic and amoebic liver abscess. Med Clin North Am 1988: 847-848.

13. Klatchko B, Schwartz S: Diagnostic and therapeutic approaches to pyogenic abscesses of the liver. Sur Gyn Obstet 1989; 168: 332-336.

14. Branum GD, Meyers WC. Pyogenic and amebis liver abscess. In: David C. Sabiston, H. Kim Lyerly, editors. Textbook of Surgery 15th ed. Philadelphia: WB Saunders Company; 1997; 1061-1068.

15. Koneru S, Peskin GW, Sreenivas V: Pyogenic hepatic abscess in a community hospital. Am Surg 1994; 60: 278-281.

16. Moore-Gillon JC, Eykyn SJ, Phillips I: Microbiology of pyogenic liver abscess. Br Med J 1981; 283: 819-821.

17. Mc Donald AP, Howard RJ: Pyogenic liver abscess. World J Surg 1980; 4: 369-380.

18. Hashimoto L, Hermann R, Grundfest-Broniatowski S: Pyogenic hepatic abscess: results of current management. Am Surg 1995; 61: 407-411.. 